\title{
The Risk of Recrystallization: Changes to the Toxicity and Morphology of Pyrimethamine
}

\author{
Zak Perold $^{1}$, Mino R Caira ${ }^{2}$, Marius Brits ${ }^{1}$ \\ ${ }^{1}$ North-West University, Potchefstroom 2520, South Africa; ${ }^{2}$ University of Cape Town, Cape Town, South Africa.
}

Received, March 9, 2014; Revised, April 16, 2014; Accepted, April 16, 2014; Published, April 21, 2014.

\begin{abstract}
PURPOSE. Pyrimethamine, an anti-malarial agent known to exhibit solid state polymorphism, may be purified by means of recrystallization. Recrystallization may alter the solid state chemistry of pharmaceuticals, which may impact the toxicity and/or manufacturability thereof. We evaluated the risks associated with the recrystallization of pyrimethamine. METHODS. Pyrimethamine was recrystallized using several organic solvents. X-ray diffraction, thermal analysis, infra-red spectroscopy, microscopy, flowability -, solubility and dissolution testing as well as computational work were employed to evaluate the recrystallized products. RESULTS. A toxic solvatomorph of pyrimethamine (Pyr-MeOH) was found to be the product from methanol recrystallization. The elucidation of - and the elaboration on the unique characteristics of Pyr- $\mathrm{MeOH}$ provides the pharmaceutical industry with several means to identify $\mathrm{Pyr}-\mathrm{MeOH}$ and to distinguish it from the pharmaceutically preferred anhydrous form (Pyr). Thermal methods of analysis found that the toxicity of Pyr$\mathrm{MeOH}$ may be reversed by overcoming a desolvation activation energy of $148 \mathrm{~kJ} / \mathrm{mol}$. In addition it was found that recrystallization altered the morphology of Pyr. Angle of repose and tapped density determinations identified that the different morphologies of Pyr displayed differences in powder flow and compressibility behaviour and In Silico calculations were successful in rendering morphologies resembling that found experimentally. CONCLUSION. We present a solvatomorph of pyrimethamine and provide several characteristic means to identify this unwanted toxic form and quantified the energy required to overcome its toxicity. In addition we describe that Pyr may present in different morphologies and show how it may impact the manufacturability thereof.
\end{abstract}

This article is open to POST-PUBLICATION REVIEW. Registered readers (see "For Readers") may comment by clicking on ABSTRACT on the issue's contents page.

\section{INTRODUCTION}

There will always remain a chance that not all the possible polymorphs and/or solvatomorphs of an active pharmaceutical ingredient (API) have been discovered (1) and it is therefore imperative for the pharmaceutical industry to stay abreast with newly discovered polymorphs and solvatomorphs to avoid problems associated with stability, treatment efficacy, safety and manufacturability (2). Pyrimethamine (Figure 1) has been used in the treatment of uncomplicated malaria for more than 30 years $(3,4)$. Different solid forms of pyrimethamine have been described as early as 1976 (5), and yet the discovery of new solid forms in 2011 and $2012(6,7)$ revealed that its solid state chemistry has still not yet been exhaustively elucidated.

Organic solvents are commonly employed in the pharmaceutical industry during processes such as purification (by means of recrystallization) and granulation $(8,9)$. The risk associated with the use of organic solvents should be governed by strict control procedures; however, the extent to which these regulations are enforced remains questionable. The WHO estimates that only $20 \%$ of countries have effective medicine regulatory authorities (10), and consequently sub-standard and/or unsafe medicines may inadvertently reach the market (11, 12).

Not so long ago, oral liquid preparations were contaminated with diethylene glycol (13) and serve as a tragic example of ineffective control over the use of organic solvents. More recently, de Villiers et al. described newly discovered toxic solvatomorphs of rifampicin which may have

Corresponding Author: Dr Marius Brits; North-West University, Potchefstroom 2520, South Africa; Email: Marius.Brits@nwu.ac.za 
resulted as a consequence of contaminated organic solvents being used during manufacturing (14).<smiles>CCc1nc(N)nc(N)c1-c1ccc(Cl)cc1</smiles>

Figure 1. The chemical structure of pyrimethamine.

Pyrimethamine and some of its derivatives are purified by recrystallization with alcohol (15-18). Recrystallization is a technique employed universally to alter the solid state chemistry of an API $(19,20)$. Organic solvents such as methanol, ethanol and acetone rank amongst the top 10 solvents which are most frequently used in pharmaceutical processes (9) and commonly result in solvatomorphism (20).

The purpose of this work was to evaluate the risks associated with the recrystallization of pyrimethamine using ICH Class II (methanol) and III (acetone, propanol and ethanol) organic solvents (21). In our work, we found it possible to prepare the methanol solvatomorph (hereinafter referred to as Pyr-MeOH) as first described by Delori et al. (7) from recrystallisation, as opposed to their technique of liquid assisted grinding. The focus of the work done by Delori et al. (7) was completely different to that which is presented herein. The work of Delori et al. (7) focused on the formation of co-crystals and salts of pyrimethamine, with the formation of Pyr-MeOH as a mere by-product of their study, being allocated, in passing, only two sentences in their manuscript (7). In particular, though they deposited the crystallographic data for this phase at the CSD (refcode XEGJEA), no description of the structure, morphology, thermodynamic properties or solubility profile were presented in their manuscript. The present account in part, serves to elaborate on the physicochemical properties of Pyr$\mathrm{MeOH}$, being distinctly unrelated to the study by Delori et al. (7). We found that recrystallization may not only risk the alteration of the toxicity of anhydrous pyrimethamine, but also its manufacturability. We present our work in an attempt to eliminate the potential health risks and manufacturing problems associated with the recrystallization of pyrimethamine using selected ICH Class II solvents.

\section{MATERIALS AND METHODS}

\section{Recrystallization}

Supersaturated solutions of anhydrous pyrimethamine (Bio-gen, India) were prepared by dissolving it in ethanol, methanol, acetone and propanol (Merck, South Africa), whilst the temperature was maintained at the boiling point of the solvent used. The supersaturated solutions were filtered and allowed to crystallize at ambient conditions until the crystal yield was sufficient for analysis (approximately 2 weeks). The anhydrous pyrimethamine raw material that was used in this work fit the description of the polymorph reported by Sethuraman and Muthiah (22) -CCDC number 193733, refcode MUFMAB.

\section{X-Ray Powder Diffraction (XRPD) and Variable Temperature X-Ray Powder Diffraction (VTXRPD)}

A Bruker D8 Advance diffractometer (Bruker, Frankfurt, Germany) was used to obtain XRPD patterns. The following conditions were applicable: target, $\mathrm{Cu}$; voltage, $40 \mathrm{kV}$; current, $30 \mathrm{~mA}$; divergence slit, $2 \mathrm{~mm}$; anti-scatter slit, $0.6 \mathrm{~mm}$, detector slit, $0.2 \mathrm{~mm}$; monochromator; scanning speed, $2 \%$ min with a step size of $0.025^{\circ}$, step time of $1.0 \mathrm{sec}$, radiation wavelength of $1.54 \AA$ and a scan range of $3-35^{\circ} 2 \theta$. For VTXRPD the same measuring conditions as above were used together with an Anton Paar TTK-450 low-temperature camera (Anton Paar, Austria) with a heating rate of $0.1 \mathrm{~K} / \mathrm{sec}$.

\section{Differential Scanning Calorimetry (DSC)}

Approximately 2-5 mg of sample was weighed into a $40 \mu \mathrm{l}$ aluminium sample pan, fitted with a pierced lid (Mettler Toledo, Greifensee, Switzerland) and crimped. The samples were analysed using a Mettler Toledo DSC823 ${ }^{\mathrm{e}}$ (Mettler Toledo, Greifensee, Switzerland) differential scanning calorimeter which was operated at a heating rate of $10 \mathrm{~K} / \mathrm{min}$ (unless stated otherwise) with a nitrogen flow rate of $80 \mathrm{ml} / \mathrm{min}$. The thermal events were evaluated by means of the $\mathrm{STAR}^{\mathrm{e}}$ software (version 9.0x) (Mettler Toledo, Greifensee, Switzerland). The instrument was calibrated using indium and zinc reference material.

\section{Thermogravimetric Analysis (TGA)}

Approximately $10-15 \mathrm{mg}$ of sample was weighed into a $100 \mu \mathrm{l}$ aluminium sample pan, fitted with a 
pierced lid (Mettler Toledo, Greifensee, Switzerland) and crimped. The samples were analysed using a Mettler Toledo TGA/SDTA851 ${ }^{\mathrm{e}}$ (Mettler Toledo, Greifensee, Switzerland) thermogravimetric analyser which was operated at a heating rate $10 \mathrm{~K} / \mathrm{min}$ (unless stated otherwise) with a nitrogen flow rate of $80 \mathrm{ml} / \mathrm{min}$. The thermal events were evaluated by means of the $\mathrm{STAR}^{\mathrm{e}}$ software (version 9.0x) (Mettler Toledo, Greifensee, Switzerland). The instrument was calibrated using indium and aliminium reference material.

\section{Karl-Fischer water determination}

A Metro-ohm (Metro- $\Omega$ ) KF Titrino (Metro- $\Omega$, Switzerland) was used in the determination of water content in samples. The apparatus was calibrated using distilled water and sodium tartrate dihydrate (Merck ${ }^{\circledR}$, Johannesburg, South Africa).

\section{Hot Stage Microscopy (HSM)}

A Nikon DS-Fil (Nikon, Tokyo, Japan) digital camera attached to a Nikon ECLIPSE E400 light microscope (Nikon, Tokyo, Japan) was used for HSM. Samples were heated with the use of a Leitz hot stage (Leica Microsystems Inc., Bannockburn, IL, USA) and the captured images were analysed using NIS-Elements F2.30 software (Nikon, Tokyo, Japan). Samples were suspended in silicone oil (Fluka, Switzerland) to visualize possible desolvation processes.

\section{Diffuse Reflectance Infrared Fourier Transform (DRIFT-IR) Spectroscopy}

The IR spectra were recorded using a Nicolet Nexus 470 spectrophotometer with the Avatar Smart diffuse reflectance accessory (Nicolet Instrument Corp., Madison, WI) over a range of $4000 \mathrm{~cm}^{-1}$ - 400 $\mathrm{cm}^{-1}$. IR samples were prepared and analyzed in a potassium bromide $\left(\right.$ Merck $^{\circledR}$, Johannesburg, South Africa) matrix.

\section{Gas Chromatography (GC)}

An Agilent 6890 Gas Chromatograph with an Agilent 7697A Headspace sampler, together with a

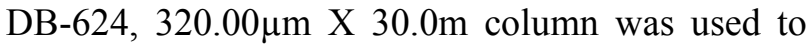
perform residual solvent testing (where applicable) according to the USP general guidelines, Chapter $<467>(23)$.

\section{Single Crystal X-ray Diffraction}

Colourless, prismatic single crystals of Pyr- $\mathrm{MeOH}$ showed poor cleavage and a tendency to produce fragments displaying multiple reflections. After several trials, a specimen was identified as suitable for full intensity data-collection. The latter was performed on a Bruker Kappa Apex Duo diffractometer with graphite-monochromated MoK $\alpha$-radiation $(\lambda=0.71073 \AA)$ and with the crystal cooled to $100(2) \mathrm{K}$ to optimise diffraction quality. Comparison of the unit cell data at room temperature $(294 \mathrm{~K})$ and $100(2) \mathrm{K}$ showed that no phase change had occurred on cooling the crystal. Intensity data-processing (SAINT, Version 7.60a, Bruker AXS Inc., Madison, WI, USA) included Lorentz-polarization corrections and multi-scan absorption corrections. For structure solution and refinement by full-matrix least-squares against $F^{2}$, programs in the SHELX-suite were employed (24).

The intensity data displayed only a centre of symmetry indicating the triclinic system; the centrosymmetric space group $P(-1)$ was deduced from the parameter $\left|E^{2}-1\right|=0.979$. Direct methods yielded all non- $\mathrm{H}$ atoms of the asymmetric unit (two molecules of the drug, designated $\mathrm{A}$ and $\mathrm{B}$, and a single molecule of methanol). All non-H atoms refined anisotropically. All $\mathrm{H}$ atoms were located in difference Fourier maps and were generally included in a riding model with isotropic thermal parameters $\left(U_{\text {iso }}\right)$ 1.2-1.5 times those of their parent atoms. Special attention was paid to the geometries of the amino groups, only one of which displayed trigonal planar geometry (that involving N14B) and was modelled as such. For the three remaining $-\mathrm{NH}_{2}$ groups, some degree of pyramidisation at the nitrogen atom was noted and modelling of the $\mathrm{H}$ atoms in these cases involved free refinement with $\mathrm{N}-\mathrm{H}$ distance restraints of $0.88(1) \AA$.

The crystallographic parameters for Pyr- $\mathrm{MeOH}$ following our X-ray analysis have been deposited at the Cambridge Crystallographic Data Centre (CCDC) (see Table 1).

\section{Solubility Studies}

The aqueous solubilities of Pyr and $\mathrm{Pyr}-\mathrm{MeOH}$ were established in $0.1 \mathrm{M} \mathrm{HCl}(\mathrm{pH} 1.2 \pm 0.05)$, acetate buffer ( $\mathrm{pH} 4.5 \pm 0.05)$ and phosphate buffer (pH $6.8 \pm 0.05)$ at 303,308 and $313 \pm 1 \mathrm{~K}$. A Heidolph RZR-2000 rotator (Heidolph, Germany) was used to rotate the sealed test tubes at $50 \mathrm{rpm}$ in a thermally controlled water bath. Five $\mathrm{ml}$ of the medium was transferred to each test tube, each containing $50 \mathrm{mg}$ of sample) and sealed. Each experiment was performed in triplicate. After $24 \mathrm{~h}$ the test tubes were removed from the instrument 
and allowed to cool, then filtered and appropriately diluted. Sample aliquots were analyzed using a Cary 50 spectrophotometer (Varian, USA) running Varian WinUV version 3.00.

$\mathrm{GC}$ found the recrystallization product from methanol to contain $6.0 \% \mathrm{w} / \mathrm{w}$ methanol. To evaluate the influence of the methanol released from the lattice of $\mathrm{Pyr}-\mathrm{MeOH}$, the solubility of pyrimethamine was tested in the same manner as above, with the only exception that an equivalent amount of methanol $(0.08 \% \mathrm{v} / \mathrm{v}, 6 \%$ with respect to the sample size) was added to the respective media.

A method was developed and validated specifically for the solubility studies. The validation parameters are described in the Supplementary Information section.

\section{Particle Size}

All samples (except for single crystal XRD, microscopy, powder flow and tapped density measurements) were slightly ground using a mortar and pestle and sieved to ensure a uniform particle size. The ground powder was sieved using a 106 $\mu \mathrm{m}$ sieve (Labotec, Midrand, South Africa) and subjected to particle size analysis. Particle size distribution measurements were performed using a Malvern Mastersizer 2000 (Malvern Instruments Ltd., Malvern, UK) fitted with a Hydro 2000SM dispersion unit using distilled water as dispersant. A cell stirrer prevented sedimentation of the dispersed particles and the latter were circulated through the sample cell by a sample pump. The acquired data were used to compute means, medians and standard deviations based on the particle population. The average $\mathrm{d}_{(0.5)}$ values obtained were $22.6 \mu \mathrm{m}$ (\% RSD $=4.8 \%)$ and $24.3 \mu \mathrm{m}(\% \mathrm{RSD}=5.8 \%)$ for the $\mathrm{Pyr}$ and $\mathrm{Pyr} \mathrm{MeOH}$ samples respectively.

\section{Scanning Electron Microscopy (SEM)}

A small amount of sample was used to cover the carbon tape that was affixed to the pin. The sample was then coated with a gold-palladium film using an IB-2 Eiko engineering ion coater inside a vacuum (Eiko Engineering, Ibaraki, Japan). The coated sample was then affixed to the microscope sample holder and analysed using a FEI Quanta 200 ESEM \& Oxford INCA 400 EDS system (FEI, Hillsboro, OR).

\section{In silico calculations}

Computational modulation studies were performed using Materials Studio ${ }^{\mathrm{TM}} 5.0$ (Accelrys Software Inc., San Diego, CA, USA) software platform. The
Bravais-Friedel-Donnay-Harker (BFDH) growth morphology (GM) and equilibrium morphology (EM) calculations within the Morphology ${ }^{\mathrm{TM}}$ module were used to predict the morphologies. BFDH, GM and EM calculations are based on mathematical theorems and assumptions, which have been extensively presented in related literature (25-27) and for this reason not presented in much detail here. In short, the BFDH method is a geometrical calculation that generates a habit taking into consideration the crystal lattice and symmetry operators in order to identify the growth faces and their growth rates. The GM method predicts a habit based on the assumption that the growth rate of a crystal face is proportional to its attachment energy, implying that faces with the lowest attachment energies are the slowest growing, and of the greatest importance to establish a habit. The EM method is similar to that of the GM method, as it also generates a habit using an energy parameter, the difference being that EM calculations use surface free energy.

The single crystal data file of anhydrous pyrimethamine (22), was retrieved from the Cambridge Crystallographic Data Centre (CCDC number 193733, refcode MUFMAB) and imported into the Material Studio platform and used for the predictions of Pyr morphologies. The single crystal data file of $\mathrm{Pyr}-\mathrm{MeOH}$ (as elucidated in this manuscript), was imported into the Material Studio platform for the Pyr-MeOH morphology predictions. BFDH calculations were performed using the fine quality setting, the Forcite energy method, a minimum $\mathrm{d}(h k l)$ of $1 \AA$ (maximum $h=5$, $k=5,1=5$ ) and the number of growing faces was limited to 300. GM and EM calculations were performed using the fine quality setting, Forcite energy method and the COMPASS forcefield. The summation method for GM and EM calculations was set to preset conditions (Electrostatic: Ewald and van der Waals: atom based). Faces for the GM calculations were controlled using preset conditions, which corresponded with those of the BFDH calculations. The habits considered to have been successfully predicted (i.e. comparable with those obtained experimentally) are presented and discussed in this manuscript.

\section{Powder flow and powder density determinations}

An Erweka GTL powder flow tester was used to characterize the powder flow of the different recrystallization products using different aperture sizes. In conjunction with the powder flow 
determinations, a Erweka SVM121 tapped density meter was used to determine the Haussner ratios and Carrs Index of the recrystallized products. Powder samples were evaluated in untreated form (i.e., not ground or sieved) in order to maintain the integrity of the crystal habit.

\section{RESULTS}

\section{Identification and classification of the recrystallization products}

The XRPD, DSC and TGA results obtained from the recrystallization products from acetone, ethanol and propanol resembled those of anhydrous pyrimethamine (Pyr) (22); however, the morphology of these products differed, and is reported under Morphology together with that of Pyr-MeOH.

We have established that Pyr-MeOH may form by means of a simple process of recrystallization, a process far more familiar and common in the pharmaceutical industry than that which is presented in the work of Delori et al. (7). Interestingly, the latter authors in fact reported that their attempt to obtain a methanol solvate by recrystallization of the API from methanol was not successful, this phase, however, being obtained via grinding the API in a small amount of methanol. This indicates the vagaries of recrystallization experiments and the potential for conflicting outcomes, which are often due to subtle differences in experimental procedures. We emphasise that our findings resulted from the specific recrystallization technique described in this paper. Figure 2 depicts the XRPD pattern of Pyr-MeOH in comparison with one of the known anhydrous forms of pyrimethamine (Pyr) $(6,22)$. Anhydrous pyrimethamine herein referred to as Pyr references to anhydrous pyrimethamine described by Sethuraman and Muthiah (22), whereas $\mathrm{Pyr}_{2}$ refers to anhydrous pyrimethamine described by Tutughamiarso and Bolte (6).

The DSC trace of Pyr-MeOH (Figure 3) revealed a broad endotherm with peak maximum at $355.4 \mathrm{~K}$ and a melting endotherm at $514.3 \mathrm{~K}$. The thermal events observed by DSC were visualized by means of HSM (Figure 3), which identified the first event as desolvation (crystal darkening and evolution of bubbles) and the second event as the melting process. In addition, HSM showed crystal growth to be concurrent with desolvation. Thermogravimetric analysis of $\mathrm{Pyr} \mathrm{MeOH}$ (Figure 3 ) indicated a mass loss of $5.7 \pm 0.2 \%$ in a single step in the region of $343-363 \mathrm{~K}$ that coincided with the temperature of desolvation as seen in the DSC of $\mathrm{Pyr}-\mathrm{MeOH}$. The thermal behaviour of Pyr$\mathrm{MeOH}$ clearly differed from that of Pyr, which exhibited a single melting endotherm at $514 \mathrm{~K}$ and no significant weight loss.

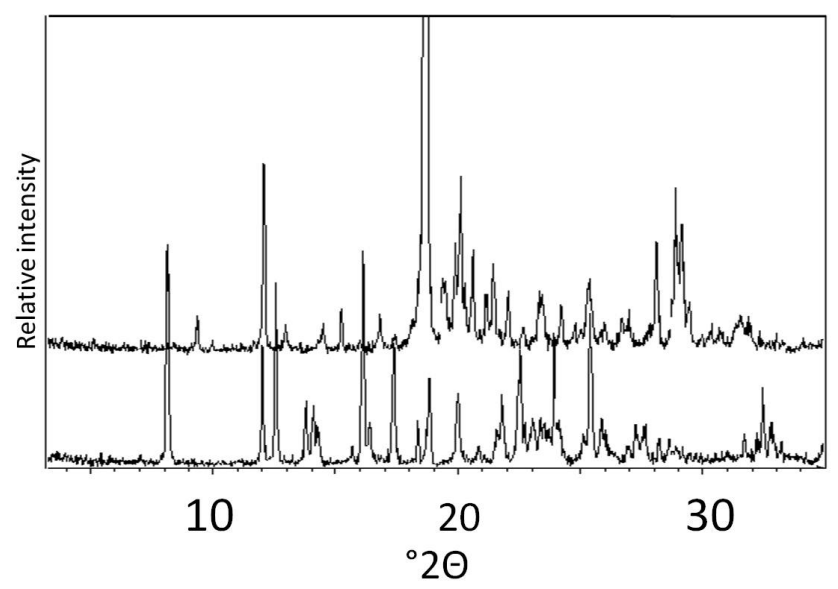

Figure 2. The XRPD patterns of Pyr (top) and Pyr$\mathrm{MeOH}$ (bottom).

GC residual solvent testing identified that methanol was present in a concentration of $6.0 \%$ $\mathrm{w} / \mathrm{w}( \pm 0.9 \% \quad \mathrm{w} / \mathrm{w})$ in Pyr-MeOH. Karl-Fischer analysis did not detect the presence of water in Pyr$\mathrm{MeOH}$, which in conjunction with the GC and TGA results, proved Pyr-MeOH not to be a hydrated phase. A theoretical mass loss of $11.4 \%$ applies to a 1:1 stoichiometry of pyrimethamine and methanol, and therefore the TGA results for Pyr$\mathrm{MeOH}(5.7 \%)$ indicated it to be a hemi-methanol solvated form of pyrimethamine (1:0.5 or $2: 1)$.

The IR spectrum of Pyr-MeOH is depicted in Figure 4 together with that of Pyr. The IR spectrum of anhydrous pyrimethamine is reported to present characteristic bands between 3500 and $1400 \mathrm{~cm}^{-1}$ and at 3467, 3310, 3149, 1913 and $1793 \mathrm{~cm}^{-1}$ (28); these are present in the IR spectra of both forms. The Discussion section elaborates on the IR spectrum of Pyr-MeOH, in conjunction with findings from its single crystal XRD data.

\section{Structural elucidation by single crystal XRD}

Table 1 lists the crystal data and refinement parameters for Pyr-MeOH and Figure 5 shows the crystallographic asymmetric unit with non-H atoms drawn as thermal ellipsoids at the $50 \%$ probability level. The unit comprises two independent molecules of the drug (A and B) and a single molecule of solvent, giving the solvate a 2:1 stoichiometry, in accord with the TGA data. 


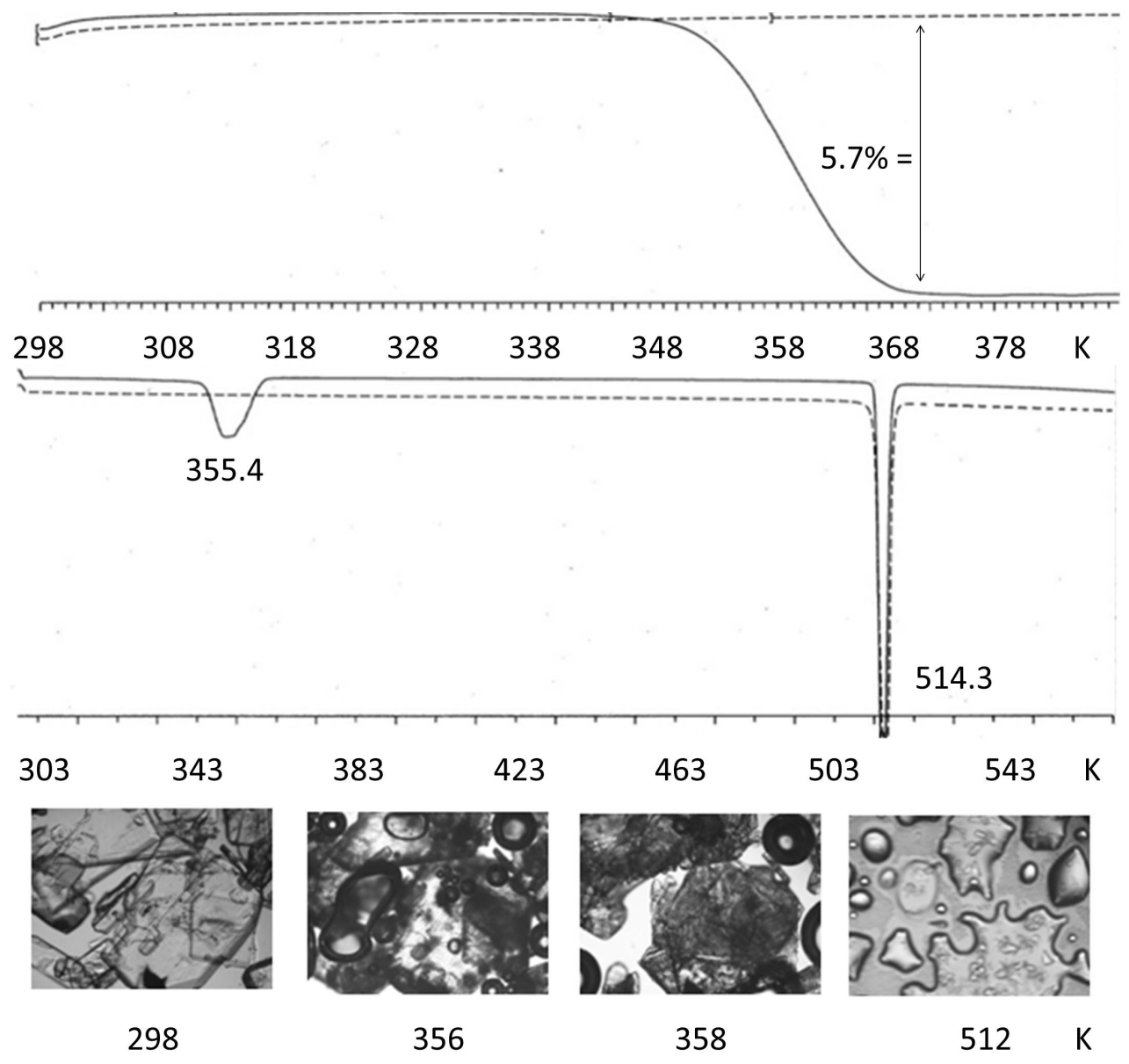

Figure 3. TGA (top) and DSC (middle) traces for Pyr (dotted lines) and Pyr-MeOH (solid lines). HSM photomicrographs of Pyr-MeOH (bottom) at 298, 356, 358 and 512K.

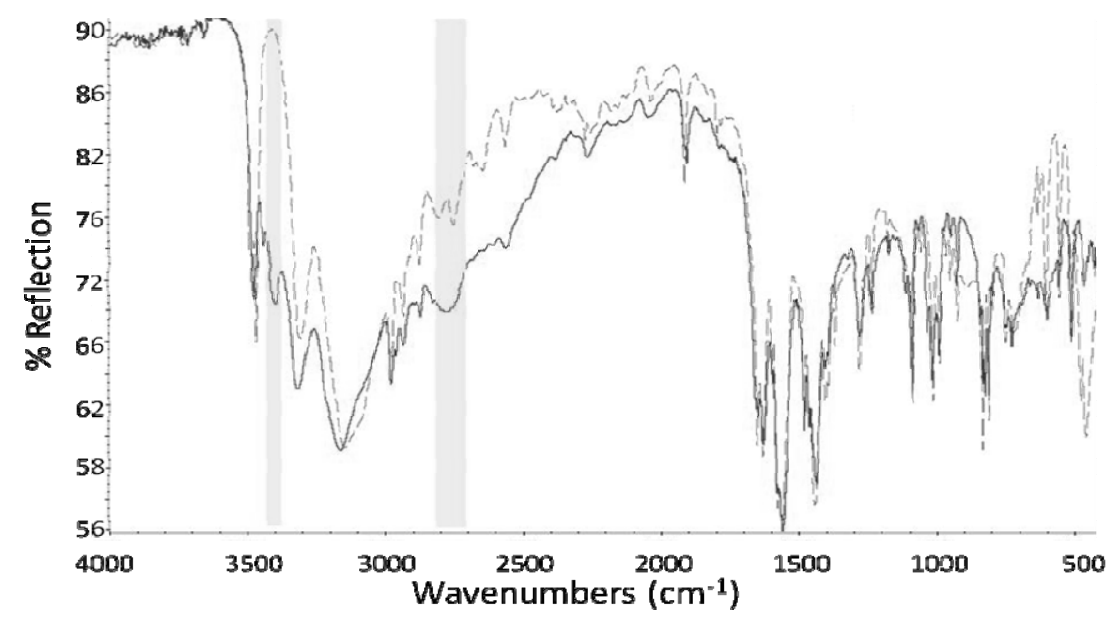

Figure 4. Superimposed IR spectra of Pyr (dotted line) and Pyr-MeOH (solid line). 
Table 1. Crystal data and refinement parameters for Pyr-

\begin{tabular}{|c|c|}
\hline Parameter & Value \\
\hline CCDC number & 868963 \\
\hline Chemical formula & $\mathrm{C}_{9} \mathrm{H}_{10} \mathrm{O}_{3} \cdot \mathrm{C}_{6} \mathrm{H}_{6} \mathrm{~N}_{2} \mathrm{O}$ \\
\hline Formula weight & 529.47 \\
\hline $\mathrm{D}_{\text {calc }}\left(\mathrm{g} \mathrm{cm}^{-3}\right)$ & 1.316 \\
\hline Crystal system & Triclinic \\
\hline Space group & $P(-1)$ \\
\hline$a(\AA)$ & $8.450(2)$ \\
\hline$b(\AA)$ & $12.659(3)$ \\
\hline$c(\AA)$ & $14.008(3)$ \\
\hline$\alpha\left(^{\circ}\right)$ & $64.441(4)$ \\
\hline$\beta\left(^{\circ}\right)$ & $89.908(4)$ \\
\hline$\left.x^{\circ}\right)$ & $82.001(4)$ \\
\hline $\mathrm{V}\left(\AA^{3}\right)$ & $1335.7(5)$ \\
\hline Formula units, $Z$ & 2 \\
\hline $\mathrm{F}(000)$ & 556 \\
\hline$\mu\left(\mathrm{MoK}_{\alpha}\right)\left(\mathrm{mm}^{-1}\right)$ & 0.277 \\
\hline Crystal size $\left(\mathrm{mm}^{3}\right)$ & $0.19 \times 0.26 \times 0.39$ \\
\hline $\mathrm{T}(\mathrm{K})$ & $100(2)$ \\
\hline$\theta$-range $\left(^{\circ}\right)$ & $1.8-30.5$ \\
\hline Total reflections & 31165 \\
\hline Unique reflections & 8018 \\
\hline $\begin{array}{l}\text { Data/restraints/ } \\
\text { parameters }\end{array}$ & $8018 / 6 / 353$ \\
\hline $\mathrm{R}_{1}($ on $\mathrm{F}>4 \sigma(\mathrm{F}))$ & 0.0369 \\
\hline $\begin{array}{l}\mathrm{wR}_{2}\left(\text { on } \mathrm{F}^{2}\right. \\
\mathrm{F}>4 \sigma(\mathrm{F}))\end{array}$ & 0.0865 \\
\hline Goodness-of fit, $\mathrm{S}$ & 1.012 \\
\hline $\begin{array}{l}\Delta \rho \max ., \text { min. } \\
\left(\mathrm{e} \AA^{-3}\right)\end{array}$ & $0.42,-0.43$ \\
\hline
\end{tabular}

The inverted counterpart of molecule $\mathrm{A}$ is nearly superimposable on molecule $\mathrm{B}$ (weighted r.m.s.-fit $=0.59 \AA$ ) and the principal conformational parameter (C5-C4-C8-C9 in molecule A, corresponding geometrically to $\mathrm{C} 3-\mathrm{C} 4-\mathrm{C} 8-\mathrm{C} 9$ in molecule B) has the respective values $-75.1(2)^{\circ}$ and $104.7(2)^{\circ}$. In each case, the ethyl group is rotated out of the plane of the phenyl ring.

Molecular association in the solvate is mediated by extensive hydrogen bonding that generates a variety of supramolecular synthons. Selfassociation of type-A molecules is shown in the centrosymmetric array of Figure 6, which includes the methanol molecule and its hydrogen bonding to the API framework. In addition to the central cyclic hydrogen bonded motif with graph set descriptor
$\mathrm{R}_{2}^{2}(8)$ (29) generated by identical N-H...N bonds $(\mathrm{N} \cdots \mathrm{N} 3.040(2) \AA)$, flanking cyclic motifs are formed with graph set $\mathrm{R}_{3}^{2}(8)$ that include atom $\mathrm{O} 19$ of the solvent molecule as a hydrogen bond acceptor, engaging in bonds with donor groups N14A-H and N15A-H (N...O distances 2.883(2) Å and 2.949(2) $\AA$ respectively). Figure 6 also shows that the hydroxyl group of the solvent molecule acts as a donor in a hydrogen bond to N12B $(\mathrm{O} \cdots \mathrm{N}$ $2.729(2) \AA$ ) and is thus very tightly bound to the API framework.

An analogous, centrosymmetric tricyclic $\mathrm{H}-$ bonded motif occurs when type-B molecules associate, as shown in Figure 7. The central $\mathrm{R}_{2}^{2}(8)$ motif again features identical $\mathrm{N}-\mathrm{H} \cdots \mathrm{N}$ bonds $(\mathrm{N} \cdots \mathrm{N}$ 3.011(2) $\AA$ ) but the flanking $\mathrm{H}$-bonded $\mathrm{R}_{3}^{2}(8)$ rings are now completed by nitrogen atom N12 of a typeA molecule $(\mathrm{N} \cdots \mathrm{N}$ distances 3.036(2) $\AA$ and 3.066(2) A).

As stated earlier, the methanol solvate of pyrimethamine, herein designated as $\mathrm{Pyr}-\mathrm{MeOH}$, was found to be the same phase as that reported by Delori et al. (7), who, however, deposited their crystallographic data $(\mathrm{T}=180 \mathrm{~K}, \mathrm{R}=0.0428)$ in the CSD without any discussion in their paper of the structural features presented here, since this phase was of peripheral interest only, their focus being on salts and co-crystals of pyrimethamine. Thus, all of the structural data presented above for $\mathrm{Pyr}-\mathrm{MeOH}$, as well as the further characterization studies reported in this paper represent previously unpublished results.

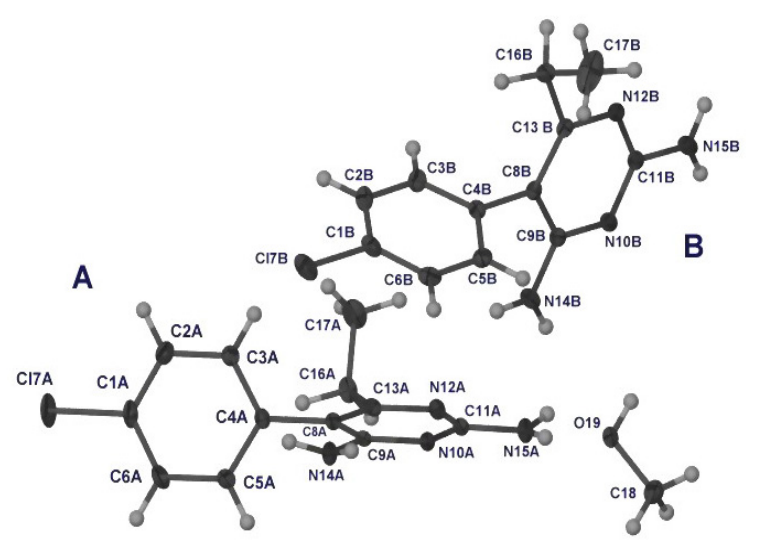

Figure 5. The crystallographic asymmetric unit in the solvate Pyr-MeOH. Non-hydrogen atoms are drawn as thermal ellipsoids at the $50 \%$ probability level and $\mathrm{H}$ atoms are drawn as spheres of arbitrary radius. 


\section{Thermodynamic stability of Pyr-MeOH}

HSM, DSC and TGA indicated that Pyr-MeOH underwent desolvation at $343-373 \mathrm{~K}$, which coincided with recrystallization (Figure 3). The melting point of the recrystallized product (post desolvation) corresponded with that of Pyr, which suggested that the desolvation of Pyr-MeOH led to crystal collapse and recrystallization into Pyr. In some cases, different polymorphic forms may have very similar melting points, and therefore it is advisable to confirm polymorphic identity by a combination of techniques. Since pyrimethamine has two known anhydrous forms, $\mathrm{Pyr}(22)$ and $\mathrm{Pyr}_{2}$ (6), we employed VTXRPD analysis (Figure 8) to identify which anhydrous form will result upon the desolvation of Pyr-MeOH. The desolvation process was evident from VTXPRD, which showed changes in the XRPD pattern of Pyr-MeOH in the same temperature range as identified by DSC and TGA. The stabilized recrystallization product (at 473K) was identified as Pyr as it corresponded with the XRPD pattern of Pyr (22).

The desolvation of Pyr-MeOH was evaluated by TGA between 320 and $383 \mathrm{~K}$ at heating rates $(\beta)$ of 2,5 and $10 \mathrm{~K} / \mathrm{min}$. The fractions of desolvation $(\alpha)$ were calculated for each heating rate (Figure 9). The Ozawa-Flynn-Wall non-isothermal method (30-32) was used to determine the activation energy required for desolvation of $\mathrm{Pyr}-\mathrm{MeOH}$ using the obtained results from the different TGA runs. The desolvation activation energy $\left(E_{a}\right)$ of $\mathrm{Pyr}-\mathrm{MeOH}$ was calculated to be $148.7 \pm 9.3 \mathrm{~kJ} / \mathrm{mol}(\mathrm{n}=9)$.

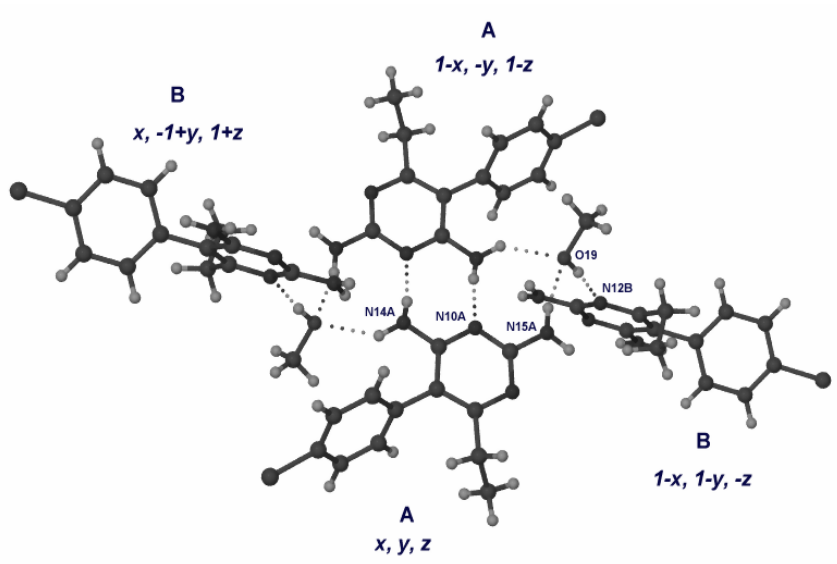

Figure 6. Self-association of type-A molecules in Pyr-MeOH and additional cyclic H-bond motifs involving the solvent molecules.

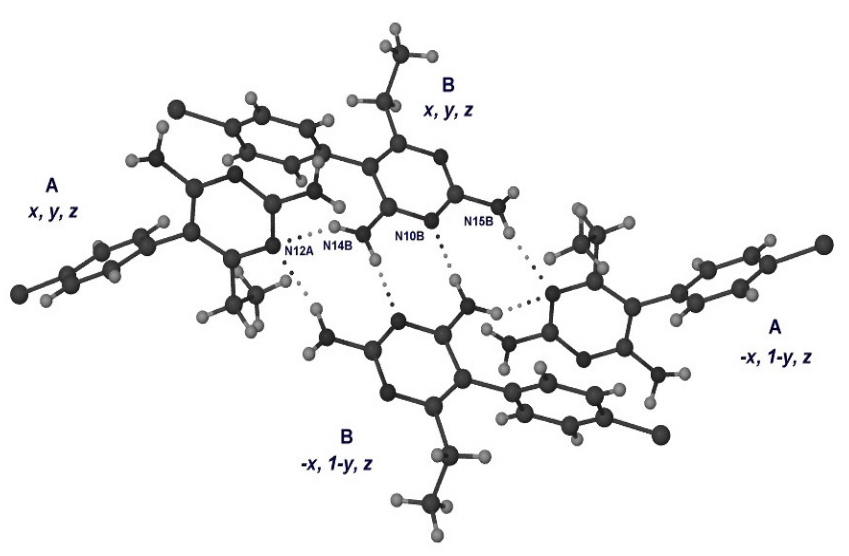

Figure 7. Self-association of type-B molecules in Pyr$\mathrm{MeOH}$ and additional cyclic H-bond motifs completed by $\mathrm{A} \cdots \mathrm{B}$ hydrogen bonds

\section{Solubility}

Solubility studies were performed on Pyr-MeOH and Pyr for comparative purposes. The solubility results are summarized in Table 2. The data showed the solubility of pyrimethamine to be indirectly proportional to the $\mathrm{pH}$ of the medium (pyrimethamine being a weakly basic compound) and also showed the solubility of Pyr-MeOH to be superior to that of Pyr in the acidic media.

The influence brought forth by the release of methanol from Pyr-MeOH (6\%) into the media was tested. The solubility of Pyr was tested in the same media containing an additional $0.08 \% \mathrm{v} / \mathrm{v}$ methanol, thereby recreating the altered media and simulating similar conditions as for $\mathrm{Pyr}-\mathrm{MeOH}$ in the unchanged media. The test was conducted at a single temperature $(308 \mathrm{~K})$, the results of which are shown in Table 2.

\section{Morphology}

As previously mentioned, the screening experiments (XRPD, DSC, TGA and IR spectroscopy) showed that the physicochemical properties of the recrystallization products from acetone and ethanol were not different from those of the starting material (Pyr). Interestingly, anhydrous pyrimethamine (Pyr) is described in literature as being needle/rod-shaped (33), whereas an investigation into the morphology of $\mathrm{Pyr}_{\mathrm{A}}$ (from acetone) and $\mathrm{Pyr}_{\mathrm{E}}$ (from ethanol) revealed that Pyr can present in morphologies other than needles. 


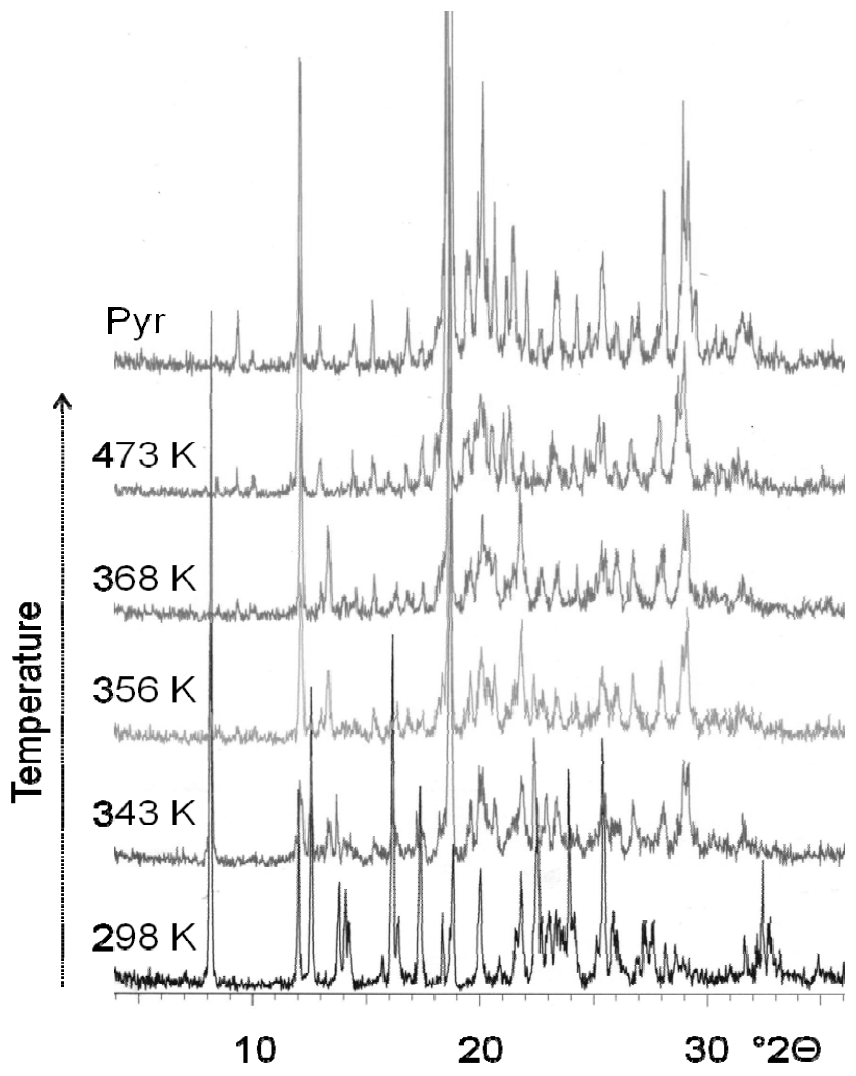

Figure 8. An overlay of the VTXRPD patterns of Pyr-MeOH at temperatures ranging between 298 and 473K together with a XRPD pattern of Pyr (at 298K).

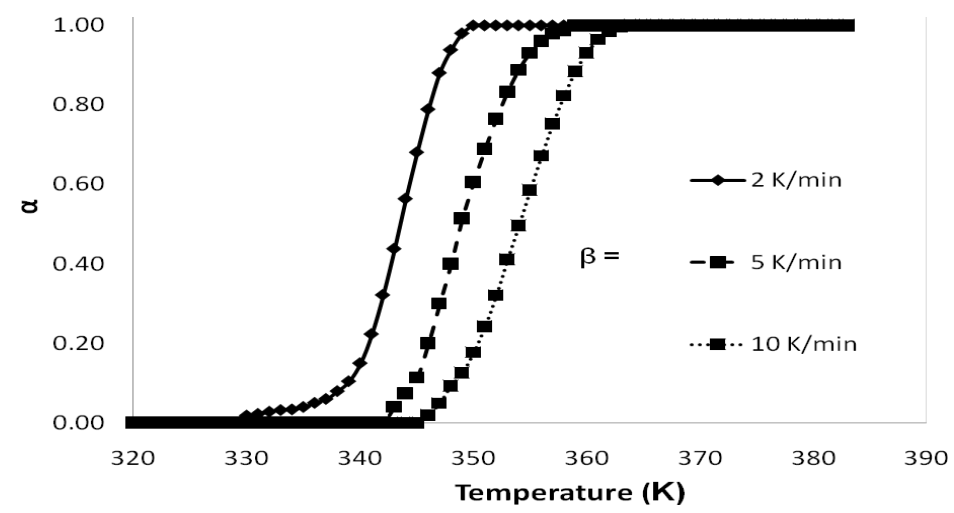

Figure 9. The desolvated fraction of $\mathrm{Pyr}-\mathrm{MeOH}(\alpha)$ as a function of temperature at different heating rates $(\beta), \beta=2,5$ and $10 \mathrm{~K} / \mathrm{min}$.

Table 2. The solubility of Pyr-MeOH in comparison with Pyr.

\begin{tabular}{ccccccc}
\hline Medium & \multicolumn{2}{c}{ Solubility of Pyr-MeOH $\mathbf{~} \mathbf{m g} / \mathbf{m l} \pm \mathbf{S D})$} & \multicolumn{3}{c}{ Solubility of Pyr $\mathbf{~} \mathbf{m g} / \mathbf{m l} \pm \mathbf{S D})$} \\
\hline & $303 \mathrm{~K}$ & $308 \mathrm{~K}$ & $313 \mathrm{~K}$ & $303 \mathrm{~K}$ & $308 \mathrm{~K}$ & $313 \mathrm{~K}$ \\
$\mathrm{HCl}$ & $3.3 \pm 0.08$ & $3.9 \pm 0.10$ & $4.3 \pm 0.10$ & $2.9 \pm 0.10$ & $3.0 \pm 0.13$ & $3.2 \pm 0.09$ \\
$\mathrm{AB}$ & $1.4 \pm 0.13$ & $1.8 \pm 0.07$ & $2.3 \pm 0.09$ & $1.3 \pm 0.06$ & $1.4 \pm 0.12$ & $1.5 \pm 0.10$ \\
$\mathrm{~PB}$ & $0.08 \pm 0.02$ & $0.07 \pm 0.03$ & $0.08 \pm 0.02$ & $0.07 \pm 0.01$ & $0.06 \pm 0.04$ & $0.07 \pm 0.02$ \\
$\mathrm{HCl}^{+}$ & NA & NA & NA & NA & $4.0 \pm 0.06$ & NA \\
$\mathrm{AB}^{+}$ & NA & NA & NA & NA & $2.0 \pm 0.16$ & NA \\
$\mathrm{PB}^{+}$ & NA & NA & NA & NA & $0.08 \pm 0.04$ & NA \\
\hline
\end{tabular}

$\mathrm{HCl}$ is $0.1 \mathrm{M}(\mathrm{pH} 1.2), \mathrm{AB}$ is acetate buffer $(\mathrm{pH} 4.5), \mathrm{PB}$ is phosphate buffer ( $\mathrm{pH} 6.8)$, and ${ }^{+}$indicates the addition of $\mathrm{MeOH}$ to the specific medium. 
The crystals that were obtained through recrystallization showed signs of fracture or imperfections (especially $\operatorname{Pyr}_{\mathrm{E}}$ ), and for this reason, computational predictions were used to elaborate on the different morphologies. The different morphologies are presented in Figure 10. Morphology calculations were successful in predicting the different crystal morphologies shown. Successful morphology renditions of $\mathrm{Pyr}_{\mathrm{A}}$ and $\mathrm{Pyr}-\mathrm{MeOH}$ were derived from $\mathrm{BFDH}$ calculations, whereas that of $\operatorname{Pyr}_{\mathrm{E}}$ was obtained from GM calculation. The morphological characteristics of the predicted morphologies are presented in Tables 3-5.

From Figure 10 (and Tables 3-5) it can clearly be seen that the morphologies of anhydrous pyrimethamine differ from the known needle/rodshaped habit (33). Powder flow/density determinations were performed in order to evaluate the potential differences brought forth by the three different morphologies of Pyr. Needle-shaped anhydrous pyrimethamine crystals were specifically prepared for this purpose by recrystallization from n-propanol $\left(\operatorname{Pyr}_{\mathrm{P}}\right)$ - Figure 11.

The powder flow and compressibility properties of the different morphologies of Pyr are given in Table 6 and illustrated in Figure 12. It was found that $\operatorname{Pyr}_{\mathrm{E}}$ was unable to pass through any aperture size, as the particles had a severe tendency towards agglomeration and clogging of the aperture (see Figure 12). Similarly $\mathrm{Pyr}_{\mathrm{P}}$ could pass through the 25 $\mathrm{mm}$ aperture only. $\mathrm{Pyr}_{\mathrm{A}}$ could not pass through the $6 \mathrm{~mm}$ aperture, but was able to pass through all subsequent larger apertures. Since $\mathrm{Pyr}_{\mathrm{E}}$ and $\mathrm{Pyr}_{\mathrm{P}}$ had difficulty passing through the various apertures, tapped density determinations were performed to provide some means to establish the powder flow characteristics of $\mathrm{Pyr}_{\mathrm{E}}$ and $\mathrm{Pyr}_{\mathrm{P}}$.
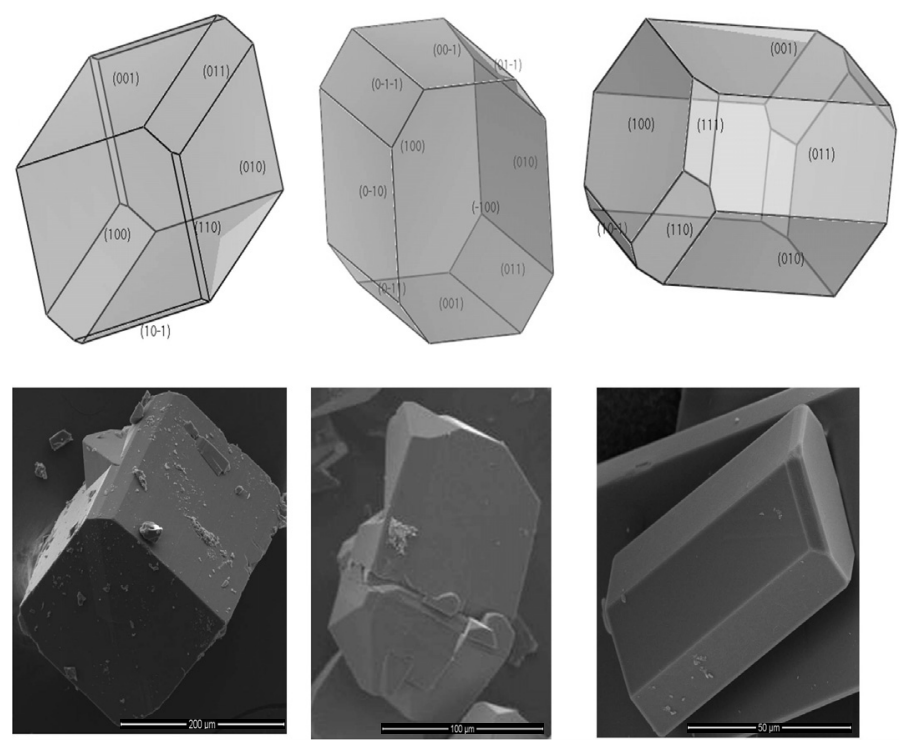

Figure 10. Calculated morphologies (top) and SEM photomicrographs (bottom) of $\mathrm{Pyr}_{\mathrm{A}}$ (left), Pyr $\mathrm{E}$ (middle), Pyr-MeOH (right).

Table 3. Predicted morphology data of $\operatorname{Pyr}_{\mathrm{A}}$.

\begin{tabular}{|c|c|c|c|}
\hline $\boldsymbol{h} \boldsymbol{k} \boldsymbol{l}$ & Multiplicity & $d_{h k l}(\AA)$ & $\%$ of total facet area \\
\hline 100 & 2 & 9.50 & 26.20 \\
\hline 010 & 2 & 10.52 & 24.66 \\
\hline 001 & 2 & 12.26 & 34.10 \\
\hline 011 & 2 & 8.86 & 8.44 \\
\hline 110 & 2 & 7.57 & 4.80 \\
\hline $10-1$ & 2 & 7.57 & 0.59 \\
\hline 111 & 2 & 6.83 & 1.207 \\
\hline
\end{tabular}


Table 4. Predicted morphology data of $\operatorname{Pyr}_{\mathrm{E}}$.

\begin{tabular}{cccccc}
\hline $\boldsymbol{h}$ & $\boldsymbol{k}$ & $\boldsymbol{l}$ & Multiplicity & $\boldsymbol{E}_{\boldsymbol{a t t}}(\mathbf{k c a l} / \mathbf{m o l})$ & \% of total facet area \\
\hline 1 & 0 & 0 & 2 & -36.99 & 37.55 \\
0 & 1 & 0 & 2 & -43.52 & 19.90 \\
0 & 0 & 1 & 2 & -46.82 & 20.64 \\
0 & 1 & 1 & 2 & -52.86 & 10.79 \\
1 & 1 & 0 & 2 & -57.60 & 1.67 \\
0 & 1 & -1 & 2 & -48.94 & 8.72 \\
1 & 1 & 1 & 2 & -64.68 & 0.73 \\
\hline
\end{tabular}

Table 5. Predicted morphology data of Pyr-MeOH.

\begin{tabular}{|c|c|c|c|}
\hline $\boldsymbol{h} \boldsymbol{k} \boldsymbol{l}$ & Multiplicity & $d_{h k l}(\AA)$ & $\%$ of total facet area \\
\hline 100 & 2 & 8.35 & 20.19 \\
\hline 010 & 2 & 11.28 & 20.92 \\
\hline 001 & 2 & 12.61 & 29.52 \\
\hline 010 & 2 & 11.28 & 20.92 \\
\hline 011 & 2 & 11.17 & 20.82 \\
\hline 110 & 2 & 7.27 & 4.66 \\
\hline $10-1$ & 2 & 7.18 & 1.88 \\
\hline 111 & 2 & 7.01 & 2.02 \\
\hline
\end{tabular}

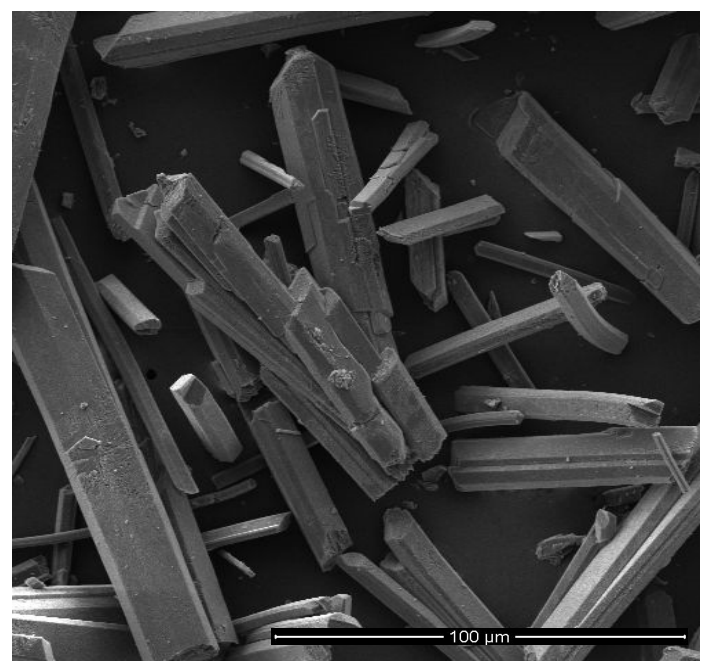

Figure 11. SEM photomicrograph of $\operatorname{Pyr}_{\mathrm{P}}$.

Table 6. The results from powder flow determinations (top) together with Hausnner ratios and Carrs indices (bottom) of $\mathrm{Pyr}_{\mathrm{A}}, \mathrm{Pyr}_{\mathrm{E}}$ and $\mathrm{Pyr}_{\mathrm{P}}$.

\begin{tabular}{|c|c|c|c|}
\hline \multicolumn{4}{|c|}{ Powder flow } \\
\hline Aperture & Pyr-A & Pyr-E & Pyr-P \\
\hline $6 \mathrm{~mm}$ & $\mathrm{NA}$ & NA & NA \\
\hline $10 \mathrm{~mm}$ & $5.8( \pm 0.2) \mathrm{g} / \mathrm{s}$ & NA & NA \\
\hline $15 \mathrm{~mm}$ & $15.1( \pm 3.6) \mathrm{g} / \mathrm{s}$ & NA & NA \\
\hline $25 \mathrm{~mm}$ & $24.3( \pm 2.9) \mathrm{g} / \mathrm{s}$ & NA & $3.6( \pm 1.2) \mathrm{g} / \mathrm{s}$ \\
\hline \multicolumn{4}{|c|}{ Carrs Index (CI) and Hausner ratio (HR) } \\
\hline Tapping time & Pyr-A & Pyr-E & Pyr-p \\
\hline 2 minutes & $\mathrm{CI}=11.8 \%$ & $\mathrm{CI}=17.6 \%$ & $\mathrm{CI}=25.1 \%$ \\
\hline & $\mathrm{HR}=0.89$ & $\mathrm{HR}=0.85$ & $\mathrm{HR}=0.80$ \\
\hline
\end{tabular}



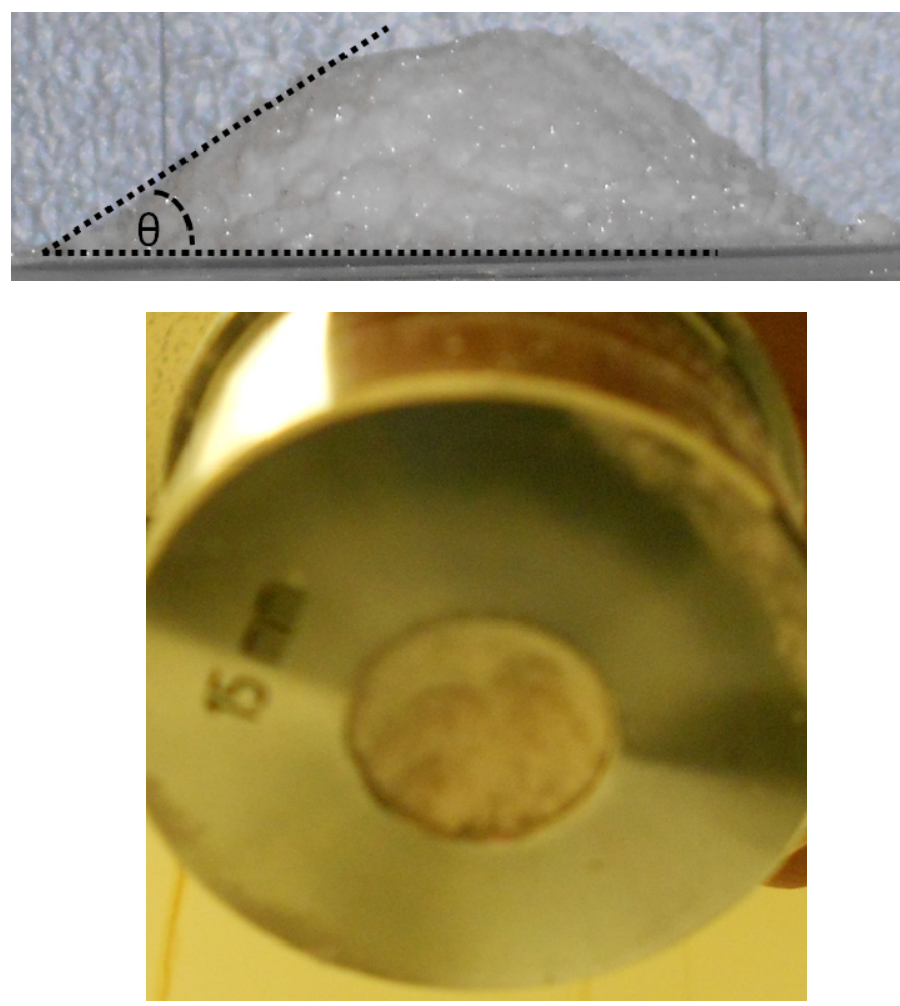

Figure 12. Angle of repose $\mathrm{Pyr}_{\mathrm{A}}$, where $\Theta=25^{\circ}\left( \pm 0.4^{\circ}\right)$ using a $25 \mathrm{~mm}$ aperture (top), and a typical example of the clogging experienced during the powder flow determinations of $\operatorname{Pyr}_{E}$ and $\operatorname{Pyr}_{P}$ (bottom).

\section{DISCUSSION}

Polymorph screening, characterization and classification

The screening studies indicated that pyrimethamine may present in a toxic methanol solvatomorphic form (Pyr-MeOH) from recrystallization. Since it is known that pyrimethamine is recrystallized with alcohols for purification purposes, we felt obligated to elaborate on the characteristics of $\mathrm{Pyr}-\mathrm{MeOH}$ (and distinguish it from the preferred form Pyr), given that a high potential exists for it to be formed during API manufacture/purification and subsequently inadvertently be used for final product manufacture.

The concentration of methanol incorporated into the lattice of $\mathrm{Pyr}-\mathrm{MeOH}( \pm 6 \%$ or $60000 \mathrm{ppm})$ greatly exceeds the maximum allowable/tolerable limit (3000 ppm) set by the ICH Q3C residual solvent guidelines (21). The inadvertent use of methanol as a recrystallization solvent, or its presence as an impurity in a non-solvating solvent used for the purification of pyrimethamine may therefore have serious health ramifications. With the public health interest at heart, we present our findings on the characterization of this form of the API and provide several unique characteristics that can be used to identify this unwanted form and distinguish it from the preferred anhydrous form (Pyr).

The XRD, DSC, TGA, DRIFT-IR properties of Pyr-MeOH clearly differed from those of Pyr. The differences between the two forms are summarized in Table 7 and serve as quick and easy analytical means to identify Pyr-MeOH and/or distinguish it from Pyr.

\section{Structure elucidation}

The main differences between the IR spectra of Pyr$\mathrm{MeOH}$ and $\mathrm{Pyr}$ were at $3400 \mathrm{~cm}^{-1}$, and in the region $2850-2650 \mathrm{~cm}^{-1}$. These are characteristic bands of methanol $(34,35)$ which confirmed the presence of methanol in the crystal of Pyr-MeOH, as they do not present in that of Pyr. Interestingly, a shift in the $-\mathrm{NH}_{2}$ band position (broad band at $3200 \mathrm{~cm}^{-1}$ ) was observed in the IR spectrum of Pyr-MeOH. A shift to a higher wavenumber (left) suggested participation in H-bonding. The shifting of the band was elucidated in the light of the findings from single crystal XRD. 
Single crystal XRD is a sophisticated and fairly expensive technique, and for this reason not routinely used during polymorphic screening studies. Nevertheless, the results from single XRD provide unequivocal crystallographic information and a reliable means of identifying a specific crystal form. Single crystal XRD yielded the unit cell parameters of $\mathrm{Pyr}-\mathrm{MeOH}$ (Table 1), which are uniquely different from those of $\operatorname{Pyr}(\mathrm{a}=9.585(2)$, $\mathrm{b}=10.806(2), \mathrm{c}=12.484(2) \AA, \alpha=79.06(1), \beta=$ 89.44(2) and $\gamma=82.37(1)^{\circ}$, with 4 molecules per unit cell, assembled in the triclinic system, space group $P(-1)$ resulting in a density of $1.313 \mathrm{~g} \mathrm{~cm}^{-3}$ ). Furthermore, only one molecule of the API in the asymmetric unit of Pyr-MeOH has a principal torsion angle value $\left(-104.7^{\circ}(2)\right)$ equal to that of a molecule in the asymmetric unit of unsolvated Pyr; instead, for the other pair of molecules, the corresponding torsion angles are $-75.1(2)^{\circ}$ in Pyr$\mathrm{MeOH}$ and $-81.2(1)^{\circ}$ in unsolvated Pyr (6).

Single crystal XRD showed that the methanol molecules of Pyr-MeOH occur as inversion-related pairs in isolated sites within the solvate crystal (Figure 13). In this arrangement the pyrimethamine molecules have a greater potential towards $\mathrm{H}$ bonding, which is depicted by the $-\mathrm{NH}_{2}$ band shift as observed in the IR spectra of Pyr-MeOH (Figure 4).

\section{Thermodynamic stability}

VTXRPD (Figure 8) confirmed that the desolvation of Pyr-MeOH led to crystal collapse and concurrent recrystallization into Pyr. The activation energy required for the desolvation of Pyr-MeOH (148.7 \pm $9.3 \mathrm{~kJ} / \mathrm{mol}$ ) is high in comparison with other known methanol solvates $(36,37)$. The high activation energy required for desolvation is supported by the single crystal data of Pyr-MeOH which found the specific topology of solvent inclusion (Figure 13) to confer additional stability on the solvated crystal structure and indicated that the collapse of this phase would require considerable energy. Since the desolvation of Pyr-MeOH resulted in its transformation into Pyr, the activation energy may be considered as an indication of how much energy is required to convert from Pyr-MeOH to Pyr.

Table 7. The characteristic differences between Pyr-MeOH and Pyr.

\begin{tabular}{lcc}
\hline \multicolumn{1}{c}{ Technique } & Pyr-MeOH & Pyr \\
\hline XRPD peaks $\left( \pm 0.2^{\circ} 2 \theta\right)$ & $8.3,12.7,13.9,14.4,16.3,19.0,20.2,22.0$, & $9.9,12.9,18.6,19.4,19.9,20.1$, \\
DSC & $22.6,23.3$ and 28.8 & $20.6,25.3,28.9$ and 29.2 \\
& Broad endotherm at 314K (desolvation) & None \\
TGA & Sharp endotherm at 514K (melt) & Sharp endotherm at 514K (melt) \\
GC & $\pm 5.7 \%$ weight loss & None \\
& Identification and quantification of & None \\
DRIFT-IR & methanol & None \\
& Peaks at 3400 and $2850-2650 \mathrm{~cm}^{-1}$ & None \\
& $($ characteristic of $\mathrm{MeOH})$ & $\mathrm{NH}_{2}$ band $\left(3200 \mathrm{~cm}^{1}\right)$ shifting
\end{tabular}

\section{Solubility}

The solubility of Pyr-MeOH was expected to differ from that of Pyr due to the influence of H-bonding and the presence of the methanol molecules within the crystal of Pyr-MeOH. We investigated the solubility behaviour of $\mathrm{Pyr}-\mathrm{MeOH}$ at different temperatures and in different media. Significant differences in the solubility behaviour of Pyr$\mathrm{MeOH}$ and Pyr provided yet another characteristic difference between the two forms (Table 2). Pyr$\mathrm{MeOH}$ was more soluble than Pyr in the acidic media. Linear relationships of solubility vs. temperature were evident in acidic media (Figure
14), which indicated that the dissolution process of both forms is of an endothermic nature.

The solubility of the two forms was equally poor in the phosphate buffer and did not differ significantly $(0.07 \pm 0.02 \mathrm{mg} / \mathrm{ml})$ regardless of the temperature. Single-sided ANOVA analysis of the solubility values of $\mathrm{Pyr}$ and $\mathrm{Pyr}-\mathrm{MeOH}$ in $0.1 \mathrm{M}$ $\mathrm{HCl}$ indicated that the solubility of $\mathrm{Pyr}-\mathrm{MeOH}$ was significantly higher $(\mathrm{p}<0.05)$ compared to that of Pyr (Figure 15) in the range 303-313 K. In acetate buffer $(\mathrm{pH} 4.5)$ the difference in solubility of the two forms was not significantly different between 303 and $306 \mathrm{~K}(\mathrm{p} \geq 0.05)$. Thus, $0.1 \mathrm{M} \mathrm{HCl}$ was 
deemed the most discriminatory medium to distinguish between Pyr and $\mathrm{Pyr}-\mathrm{MeOH}$ by means of solubility.

From the solubility results it is believed that the release of methanol from the crystal of Pyr- $\mathrm{MeOH}$ changed the composition of the medium and by doing so created a more favourable environment for the dissolution of pyrimethamine. This theory was investigated by repeating the solubility testing of Pyr in the same media each containing $0.08 \% \mathrm{v} / \mathrm{v}$ methanol (equivalent to the release of $6 \%$ methanol from a $50 \mathrm{mg}$ sample). The results (highlighted in Table 2) showed that adding methanol to the medium resulted in a significant increase in the solubility of Pyr, and that its measured solubility was similar to that of $\mathrm{Pyr}-\mathrm{MeOH}$ at the same temperature $(308 \mathrm{~K})$. The additional methanol potentiated the solubility of Pyr by $30 \%, 29 \%$ and $17 \%$ in $\mathrm{HCl}$, acetate buffer and phosphate buffer respectively.
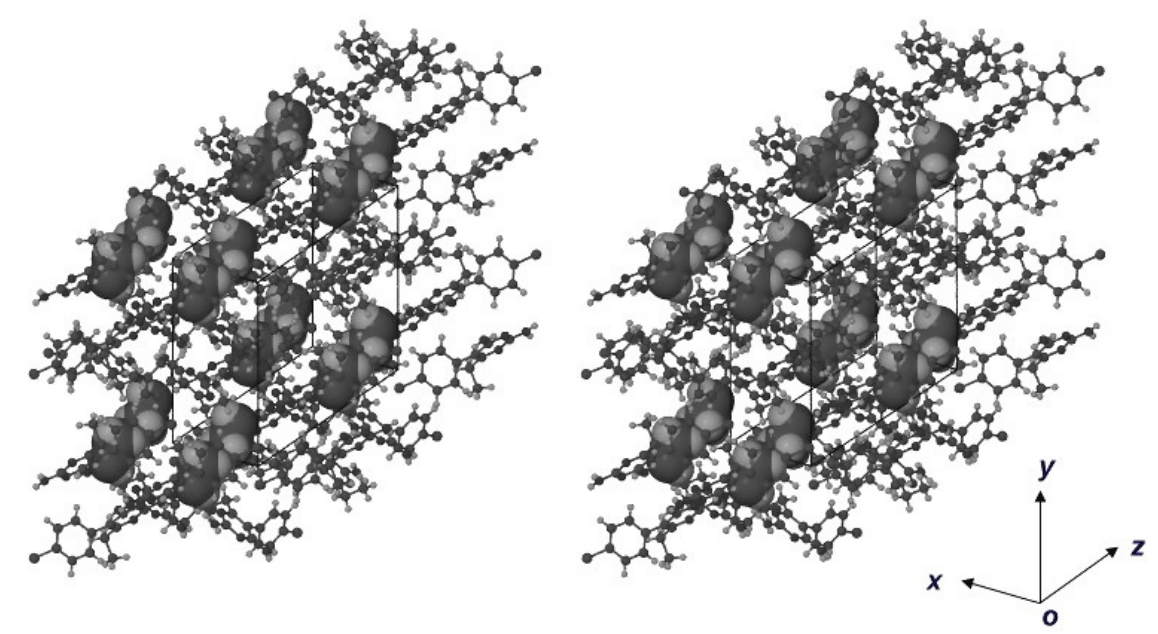

Figure 13. Stereoview of the crystal structure of Pyr-MeOH with the atoms of the API in ball-and-stick style and the solvent molecules in space-filling style.

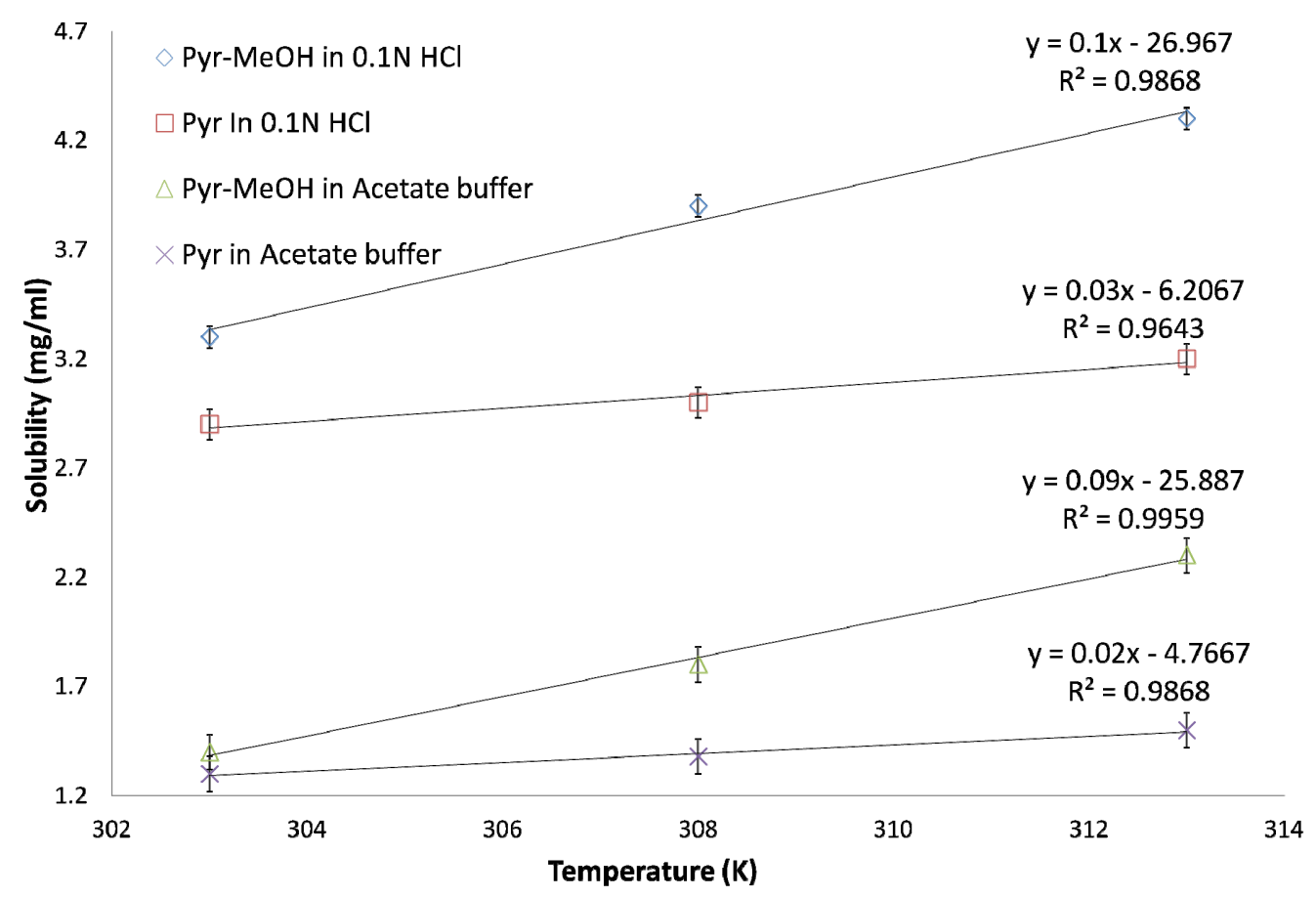

Figure 14. The solubility of $\mathrm{Pyr}-\mathrm{MeOH}$ and $\mathrm{Pyr}$ in $0.1 \mathrm{M} \mathrm{HCl}(\mathrm{pH} 1.2)$ and acetate buffer $(\mathrm{pH} 4.5)$ as a function of temperature (error bars represent the standard deviation). 


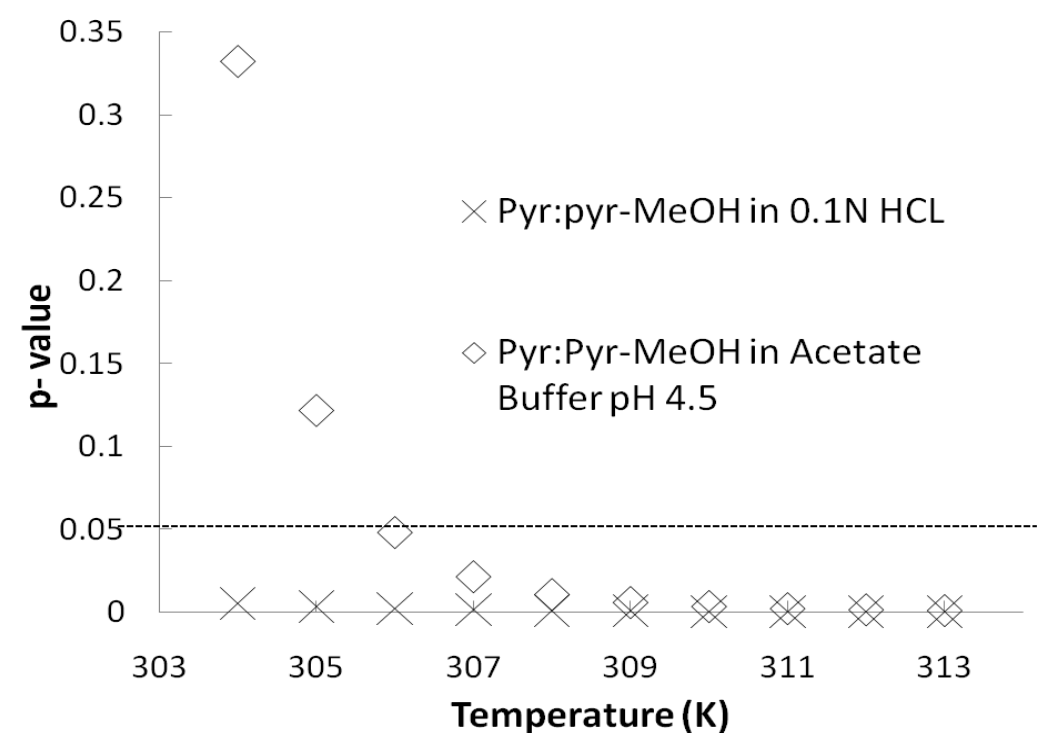

Figure 15. Calculated p-values showing the statistical significance of the differences in solubility between Pyr and Pyr$\mathrm{MeOH}$ in $0.1 \mathrm{M} \mathrm{HCl}$ and acetate buffer $(\mathrm{pH} 4.5)$.

\section{Morphology}

Recrystallization using other solvents (ethanol, acetone and propanol) did not result in any internal crystal or toxicological modification of Pyr, but did show that the triclinic form of Pyr [space group $P(-$ 1)] may crystallize in habits other than needles/rods (33). SEM photomicrographs showed that the different morphologies of $\mathrm{Pyr}$ and $\mathrm{Pyr}-\mathrm{MeOH}$ exhibit imperfections and/or signs of fracture. The experimental findings from SEM were duly complemented using crystal morphology predictions. The characteristic details of these different morphologies are listed in Tables 3-5. The predicted morphology from $\mathrm{BFDH}$ calculation resembled that of $\mathrm{Pyr}_{\mathrm{A}}$. The derived lattice parameters were $a=9.58 \AA, b=10.81 \AA, c=12.48$ $\AA$ and $\alpha=79.1^{\circ}, \beta=89.4^{\circ}, \gamma=82.4^{\circ}$. The predicted morphology derived from the GM calculations resembled that of $\mathrm{Pyr}_{\mathrm{E}}$. The derived lattice parameters were $a=9.31 \AA, b=10.74 \AA, c=12.04$ $\AA, \alpha=79.1^{\circ}, \beta=91.5^{\circ}$ and $\gamma=88.7^{\circ}$. The derived lattice parameters of the predicted morphology of Pyr-MeOH (from BFDH calculation) were $a=8.45$ $\AA, b=12.659 \AA, c=14.008 \AA, \alpha=64.44^{\circ}, \beta=$ $89.91^{\circ}$ and $\gamma=82.00^{\circ}$. The lattice parameters were in good agreement with the experimental findings from the single crystal XRD work (Table 1).

It is well known that coarse spherical particles will have the best powder flow (38). The powder flow and density results (Table 6) yielded the order of improving powder flow as $\operatorname{Pyr}_{\mathrm{P}}<\operatorname{Pyr}_{\mathrm{E}}<\operatorname{Pyr}_{\mathrm{A}}$. Understandably so, the powder flow of $\operatorname{Pyr}_{\mathrm{A}}$ was the best since the particles were coarse $(>100 \mu \mathrm{m})$ and of all the habits, the closest to being spherical, which allowed for relatively free-flowing powder. The particles of $\mathrm{Pyr}_{\mathrm{P}}$ and $\mathrm{Pyr}_{\mathrm{E}}$ were smaller and had greater surface-to-volume/mass ratios, which caused higher cohesive and adhesive forces, impairing their powder flow.

\section{CONCLUSION}

Pyrimethamine was recrystallized using acetone, $n$ propanol, ethanol and methanol to evaluate whether recrystallization with these solvents might affect the toxicity and manufacturability of the API. We presented a simple and reproducible recrystallization method to prepare a methanol solvate of pyrimethamine as an alternative to that described by Delori et al. (7).

The methanol content entrapped in the crystal of Pyr-MeOH (approximately 6\% by mass) greatly exceeds the allowable limits provided by the ICH Q3C guidelines for residual solvent content, and therefore is deemed a health risk, should this form, even in relatively small quantity, inadvertently be included in final pharmaceutical products. Pyr$\mathrm{MeOH}$ was comprehensively characterized, and the characteristics unique to this form were highlighted to serve as means to identify it and to distinguish it from the preferred anhydrous form (Pyr) in an attempt to minimize the risk of this toxic form inadvertently being incorporated into a final pharmaceutical product. It has now been established that there are at least two ways in which the methanol solvate of pyrimethamine can arise, 
namely via recrystallization from $\mathrm{MeOH}$ or during grinding of the API in the presence of MEOH (7). Furthermore, seeing that an estimated $80 \%$ of countries have poor (or even no) regulatory control over medicines and their manufacture (10), the possibility exists that incorrect solvents may be used, as illustrated by the Haiti tragedy involving toxic diethylene glycol that had contaminated oral liquid preparations (13).

VTXRPD indicated that the desolvation of Pyr$\mathrm{MeOH}$ resulted in its transformation into Pyr. The $\mathrm{H}$-bonding patterns and the topology of methanol molecule inclusion (from single crystal XRD) led to the prediction that considerable energy would be required to eliminate the toxic solvent from the crystal. Non-isothermal reaction kinetics by TGA vindicated the single crystal XRD findings, as the desolvation activation energy was quantified as $148.7 \pm 9.3 \mathrm{~kJ} / \mathrm{mol}$, which is considerably higher than values reported previously for other methanol solvates $(36,37)$.

Recrystallization with other solvents did not modify the internal crystal structure of Pyr; however, it was established that Pyr may present in different crystal habits. Computational work was successful in predicting morphology renditions comparable with those observed experimentally by SEM, and show that in-silico morphology predictions may be useful to complement experimental work. From powder flow experiments it was illustrated that these different morphologies have significantly different powder flow and compressibility behaviors, which may cause manufacturing difficulties.

\section{SUPPLEMENTARY INFORMATION}

UV spectrophotometry method development and crystallographic files include the CCDC Data Deposition confirmation, the CIF file and the CHECKcif report.

\section{ACKNOWLEDGEMENTS}

Z.P and M.B thank the Drug Research and Development unit and the Research Institute for Industrial Pharmacy of the North-West University (NWU) for financial assistance. Z.P further thanks the Laboratory for Applied Molecular Modelling (NWU), Accelrys Inc. (San Diego, USA) and the Centre for High Performance Computing (CHPC) for the help, use and licensing of Materials Studio.
M.R.C. thanks the University of Cape Town and the NRF (Pretoria) for research support.

\section{REFERENCES}

1. Price SL. The computational prediction of pharmaceutical crystal structures and polymorphism. Adv Drug Deliver Rev, 2004; 56:301-319.

2. Bauer J, Spanton S, Henry R, Quick J, Dziki W, Porter W, Morris J. Ritonavir: An extraordinary example of conformational polymorphism. Pharm. Res, 2001; 18:859-866.

3. Pyrimethamine monograph, in Wade A (ed), Martindale The Extra Pharmacopeia. 27th ed., Jarold and Sons ltd, Great Britain, pp 354-357, 1979.

4. Tracy, JW.; Webster, L.T., Chemotherapy of parasitic infections - Drugs used in the chemotherapy of protozoal infections: Malaria, in Hardman JG: Limbird LE: Gilman AG (eds), The Pharmacological Basis of Therapeutics. 10th ed., McGraw-Hill Medical Publishing Division, New York, pp 1059-1068, 2001.

5. Rees, RWA, Chai, SY, Winkley, MW, Russell, PB. Antimalarial activity of some novel derivatives of 2,4-diamino-5-(p-chlorophenyl)-6-ethylpyrimidine (pyrimethamine). J. Med. Chem. 1976; 19:723-725.

6. Tutughamiarso M, Bolte M. A new polymorph and two pseudopolymorphs of pyrimethamine. Acta Cryst, 2011; C67:0428-0434.

7. Delori A, Galek PTA, Pidcock E, Jones W. Qauntifying Homo- and Heteromolecular Hydrogen Bonds as a guide for adduct formation. Chem. Eur. J, 2012; 18:6835-6846.

8. Grodowska K, Parczewski A. Organic solvents in the pharmaceutical industry. Acta Pol Pharm, 2010; 67:3-12.

9. Constable DJC., Jimenez-Gonzalez C, Henderson RK. Perspective on solvent use in the pharmaceutical industry. Org Process Res Dev, 2007; 11:133-137.

10. World Health Organization. [Internet]. EHO policy perspectives on Medicines - Effective medicine regulation: ensuring safety, efficacy and quality. [updated 2003, cited March 2012]. Available online at

http://whqlibdoc.who.int/hq/2003/WHO_EDM_200 3.2.pdf

11. Gaudiano MC, Di Maggio A, Cocchieri E, Antoniella E, Bertocchi P, Alimonti S, Valvo L. Medicines informal market in Congo, Burundi and Angola: counterfeit and sub-standard antimalarials. Malar J, 2007; 6:22.

12. Odeniyi MA, Adegoke OA, Adereti RB, Odeku OA, Itiola OA. Comparitive analysis of eight brands of sulfadoxine-pyrimethamine tablets. Trop J Pharm Res, 2003; 2(1):161-167. 
13. Woolf A. The Haitian diethylene glycol poisoning tragedy: A dark wood revisited. J Am Med Assoc, 1998; 279(15):1215-1216.

14. De Villiers MM, Caira MR, Li J, Strydom SJ, Bourne SA, Liebenberg W. Crystallization of toxic glycol solvates of rifampicin from glycerine and propylene glycol contaminated with ethylene glycol or diethylene glycol. Mol Pharm, 2011; 8(3):877888.

15. Jacob RM. Production of 2:4-diamino-5-(4'chlorophenyl)-6-ethylpyrimidine. United States patent office, 1954; patent number 2,680,740.

16. Hitchings GH, Russell PB, Falco EA. 2,4-diamino5-phenyl-6-akyl-pyrimidines. Unites States patent office, 1951; patent number 2,576,939.

17. Rosowksy A, Dey AS, Battaglia J, Modest EJ. Synthesis of 2,4-diamino-9H-indeno[2,1-d] pyrimidines. J Heterocycl Chem, 1969; 6(5):613622.

18. Russell PB, Hitchings GH. 2,4-diaminopyrimidines as antimalarials. III. 5-Aryl derivatives. J Am Chem Soc, 1951; 3763-3770.

19. Buckton, G., Solid-state properties, in Aulton ME: editor, Pharmaceutics: The science of dosage form design. $2^{\text {nd }}$ ed., Churchill Livingstone, New York, NY, pp. 141-152, 2002.

20. Byrn, S.R.; Pfeiffer, R.R.; Stowell, J.G., Solid-state chemistry of drugs. SSCI, West Lafayette, IND, USA, 1999.

21. European Medicines Agency. [Internet]. ICH Q3C (R4) CPMP/ICH/283/95. Impurities: Guidelines for residual solvents. [updated 2009, cited March 2012]. Available online at http://www.ema.europa.eu/docs/en_GB/document_li brary/Scientific_guideline/2009/09/WC500002674.p df

22. Sethuraman V, Muthiah T. Hydrogen-bonded supramolecular ribbons in the antifolate drug pyrimethamine. Acta. Crystallogr, 2002; 58:817818.

23. United States Pharmacopeia National Formulary [Internet]. General Chapter $<467>$ Residual solvents. [updated 2014, cited 2014]. Available online at http://www.uspnf.com

24. Sheldrick GM. A short history of SHELX. Acta Crystallogr, 2008; A64:112-122.

25. Beyer T, Day GM, Price SL. The prediction, morphology and mechanical properties of the polymorphs of paracetamol. J. Am. Chem. Soc, 2001; 123:5086-5094.

26. Rohl AL. Computer prediction of crystal morphology. Curr. Opin. Solid. St. M, 2003; 7:2126.

27. Coombes, DS, Catlow RA, Gale JD, Hardy MJ, Saunders MR. Theoretical and experimental investigations on the morphology of pharmaceutical crystals. J. Pharm. Sci, 2002; 7:1652-1658.
28. De Araújo MVG, Vieira EKB, Lázaro GS, Conegro LDS, Ferreira OP, Almeida, LE, Barreto LS, da Costa NB, Gimenez IF. Inclusion complexes of pyrimethamine in 2-hydroxypropyl- $\beta$-cyclodextrin and molecular modelling. Bioorg. Med. Chem, 2007; 15:5752-5759.

29. Etter MC, MacDonald JC. Graph-set analysis of hydrogen-bond patterns in organic crystals. Acta. Crystallogr, 1990; B46:256-262.

30. Ozawa TA. new method of analysing thermogravimetric data. Bull. Chem. Soc. Jpn, 1965; 11:1881-1886.

31. Flynn JH. Early papers by Takeo Ozawa and their continuing relevance. Thermochim. Acta, 1996; 283:35-42.

32. Flynn JH, Wall LA. A quick, direct method for the determination of activation energy from thermogravimetric data. Pol. Lett, 1966; 4:323-328.

33. Hitchings GH, Russell PB, Falco EA. Process for preparation of 4-amino-5-aryl-pyrimidines. United States patent office, 1952; patent number 2,602,794.

34. Coates J. Interpretation of infrared spectra, a practical approach, in Meyers RA (ed), Encyclopaedia of analytical chemistry. John Wiley \& Sons Ltd, Chichester, pp 10815-10837, 2000.

35. Boehm G, Dwyer M. Infrared spectrum of methanol. J Chem Educ, 1981; 58(10):809-811.

36. van Tonder EC, Mahlatji MD, Malan SF, Liebenberg W, Caira MR, de Villiers MM. Preparation and physicochemical characterization of 5 Niclosamide solvates and 1 hemisolvate. AAPS Pharm Sci, 2004; 5:86-95.

37. Hakanen A, Laine E. Characterization of two terfenadine polymorphs and a methanol solvate: kinetic study of the thermal rearrangement of terfenadine from the methanol solvate to the lower melting polymorph. Thermochim. Acta, 1995; 248:217-227.

38. Staniforth J., Powder flow, In Aulton ME (ed): Pharmaceutics. The science of dosage form design. $2^{\text {nd }}$ ed., Harcourt Publishers Limited, London, UK pp 197-212, 2002. 